\title{
GARÚA EN CANARIAS Y AMÉRICA
}

\author{
ANA ISABEL NAVARRO CARRASCO \\ (Universidad de Alicante)
}

\begin{abstract}
RESUMEN
The Diccionario de la Real Academia Española in its last edition of 1992 (DRAE-92) registers the word garía 'drizzle' localized in America. It is true that the word is used in America. This is confirmed in the present article by consulting Spanish language dictionaries, general dictionaries of Americanisms as well as dictionaries and vocabularies from the various Latin American countries. However, on consulting the map for «Llovizna» in the Atlas Lingüistico $y$ Etnografico de las Islas Canarias (ALEICan) it becomes clear that the word is commonly used in the Canary Islands. Also, we have documented it with the help of vocabularies and other dialectal studies of Canarian Spanish. If the word is used in the Canary Islands, can it still be considered an Americanism? Or is it rather a Canarian dialectalism - originated in the Portuguese - that spread from the Islands to the New World?
\end{abstract}

El Diccionario de la Real Academia en su última edición de 1992 (DRAE-92) registra la voz garía con localización en América y el significado de 'llovizna'.

1 Real Academia Española, Diccionario de la lengua española, Espasa-Calpe, Madrid, 1992, $2 I^{a}$ edición, s. v. garía. Acerca de la inclusión de americanismos en los diccionarios generales de la lengua española dice M. Alvar Ezquerra: «no es sino en el [siglo] XIX cuando los indigenismos resultan abundantes, y en el XX frecuentes», en «La recepción de americanismos en los diccionarios generales de la lenguil», en H. López Morales y $\mathrm{M}^{\mathrm{a}}$. Vaquero (Editores), Actas del I Congreso Internacional sobre El español de América, San Juan, Puerto Rico, del 4 al 9 de octubre de 1982, Academia Puertorriqueña de la Lengua Española, Puerto Rico, 1987, págs. 209-218: pág. 210. Vid., además, G. Haensch, «Algunas consideraciones sobre la problemática de los diccionarios del español de América», en Lingüística Española Actual, II/2 (1980), págs. 375-384: 375-376. Vid. también, a este respecto, M. Seco, «El léxico hispanoamericano en los diccionarios de la Academia española», BRAE, LXVIII (1988), págs. 85-98. Acerca de americanismos no registrados por el Diccionario Académico, vid. R. Richard (Coordinador), Diccionario de hispanoamericanismos no recogidos por la Real Academia, Cátedra, Madrid, 1997. 
También recoge garuar con la misma localización y el significado de 'lloviznar'2. La edición anterior de 1984 ofrecía, así mismo, garúa con la misma significación pero anteponía a la localización de América la de Murcia ${ }^{3}$. Como podemos apreciar la Academia en su última edición ha suprimido la localización de Murcia. Por otro lado, garúa o formas afines no figuran en García Soriano ${ }^{4}$.

Efectivamente, el término garía está muy generalizado en América. Vargas Llosa Io recoge muchas veces en su novela La tía Julia y el escribidor ${ }^{5}$. La acción de esta entretenida y divertida novela se desarrolla en Lima en los años cincuenta. Mario Vargas Llosa narra las peripecias de los amoríos entre el joven Marito de dieciocho años y la tía Julia de treinta y dos, hermana de la mujer de su tío Lucho. Varquitas estudiaba Derecho pero su verdadera vocación era ser escritor. Y sólo llegaba a la altura de escribidor porque sus breves narraciones no gozaban de buena fortuna. Además de estudiar y escribir, la tarea que más le ocupaba era su trabajo en Radio Panamericana. Es muy curioso en La tía Julia y el escribidor, el hecho de que el hilo de la acción principal se vea interrumpido, en los capítulos impares, por breves narraciones, relatos de un capítulo que terminan siempre en suspense.

Al desarrollarse la historia en Lima, el autor ha introducido el español limeño en su novela, y, como resultado, nos ofrece una obra plagada de americanismos. Entendemos por americanismos ${ }^{6}$ aquellas voces que se usan en el español de América y que el hablante de España ni utiliza ni conoce. Es decir, no consideramos americanismos términos como canoa, cacique, tomate, chocolate, hanaca, maíz, tabaco, etc., que, aunque son de origen americano, están tan arraigados en la lengua española de acá que son consideradas voces españolas.

\footnotetext{
2 DRAE-92, s. v. garuar.

Real Academia Española, Diccionario de la lengua española, Espasa-Calpe, Madrid, 1984, $20^{a}$ edición, 2 tomos, s. v. garía.

4 J. García Soriano, Vocabulario del dialecto murciano, Editora Regional, Murcia, 1980, edición lacsímile de la primera, Madrid, 1932.

5 M. Vargas Llosa, La tía Julia y el escribidor, Seix Barral, Barcelona, 1977. Citamos por la séptima edición, Seix Barral, Barcelona, 1984.

6 Sobre el concepto de americanismo pueden verse los siguientes trabajos: J. P. Rona, «Qué es un americanismo?», en El Simposio de México, enero de 1968, actas, informes y comunicaciones, Méjico, 1969, págs. 135-148; Ídem, Aspectos metodológicos de la dialectología hispanoamericana, Montevideo, 1958; G. Haensch y R. Werner, «Un nuevo diccionario de americanismos: Proyecto de la Universidad de Augsburgos, Thesaurus. Boletin del Instituto Caro y Cutervo, XXIII (1978), Bogotá, citamos por la separata, págs. 1-40; G. Haensch, «Algunas consideraciones sobre la problemática de los diccionarios del español de América», loc. cit.; A. Rabanales, Introducción al estudio del español de Chile. Determinación del concepto de chilenisno, Publicaciones del Instituto de Filología, Sección del Instituto de Investigaciones Histórico-culturales de la Facultad de Filosofía y Educación, Universidad de Chile, Anexo $n^{\circ} 1$ del Boletín de Filología, Santiago, 1953; J. J. Montes Giraldo, Dialectología y geografia lingiística. Notas de orientación, Instituto Caro y Cuervo, Bogotá, 1970, págs. 53-55, especialmente; J. Gútemberg Bohórquez C., Concepto de 'americanismo' en la Historia del español. Punto de vista lexicológico y lexicográfico, Publicaciones del Instituto Curo y Cuervo, Bogotá, 1984
} 
Entendemos por americanismos aquellos términos que se usan en Hispanoamérica y cuyo significado es desconocido por el hablante de España y que, si vislumbra su sentido, se debe al contexto en el que se hallan situados. Estas voces pueden ser de origen americano, o bien de origen castellano con significado distinto, por no hablar de galicismos, anglicismos o italianismos, tan comunes en el español de América. En el sentido expuesto coincidimos con Haensch y Werner cuando dicen:

en el nuevo diccionario sólo se incluirán unidades léxicas que o bien no se usan en el español peninsular o bien presentan diferencias en el uso americano frente al peninsular?

Nuestra pretensión en las páginas que siguen es comprobar si la localización de garúa que da el Diccionario de la Real Academia Española (DRAE-92) es la acertada o si, en cambio, no lo es.

Veamos algunos ejemplos de la palabra en su contexto tomados de La tía Julia y el escribidor:

mientras la garúa nos mojaba los pelos y la ropa ${ }^{8}$.

y una garúa tenaz que aguantaba el aire".

se reía, en la neblina, en la garúa, en la noche, contento de su ocurrencia, y en eso oyó el ruido ${ }^{10}$.

La garía había cesado".

La garúa nos iba humedeciendo ${ }^{12}$.

La construcción [...] es hoy una endeble fábrica reparchada que resiste de milagro, no ya los témblores, incluso los moderados vientos limeños y hasta la discretísima garúa ${ }^{13}$.

bajábamos cabizbajos y de la mano por la calle Belén, húmeda de garúa ${ }^{14}$.

«Un nuevo diccionario de americanismos...», loc. cit., pág. 23.

La fía Julia y el escribidor, op.cit., pág. 22. La cursiva es nuestra.

Ibídem, pág. 78. La cursiva es nuestra.

lbidem, pág. 81. La cursiva es nuestra.

lbídem, pág. 87. Lá cursiva es nuestra.

Ibídem, pág. 111 . La cursiva es nuestra.

Ibídem, pág. 251. La cursiva es nuestra.

14 Ibídem, pág. 279. La cursiva es nuestra. Vid., además, garía en págs. 284, 359 y 394. Acerea de los americanismos en esta obra de M.Vargas Llosa, vid. nuestro trabajo «Americanismos en La tía Julia y el escribidor», en C. Hernández, G. de Granda, C. Hoyos, V. Fernández, D. Dietrick, Y. Carballera (Coordinadores), El español de América. Actas del III Congreso 
Casares en su Diccionario dice de garúa que es un término de la «Marina» que significa 'llovizna' 15 . No indica localización por lo que podemos deducir que se trata de una voz del español general. Lo que sucede es que el autor da como generales en su Obra todas las voces de uso americano que hemos buscado, pues no indica localización alguna ${ }^{16}$.

María Moliner con la etiqueta de «Marina» e «Hispam.» dice que es 'Ilovizna'"

M. Alvar Ezquerra localiza garía en América, afirma que es término de la «Marina» y liene el significado de "llovizna' ${ }^{\prime}$.

Hemos visto que el término como voz de uso americano está bien documentada en los diccionarios de lengua española. Veamos ahora los diccionarios generales de americanismos.

Alcedo afirma lo siguiente: «nombre que dan en el Perú a la lluvia menuda y cuasi imperceptible, que no incomoda, como la niebla cuando caes ${ }^{19}$. Morínigo lo localiza en América Central, América Meridional y Cuba con el significado de 'llovizna,"2l y da el origen de la voz: «del portugués dialectal caruja, niebla, que dio garuja y garúa en Canarias» ${ }^{21}$. Santamaría dice que es voz quichua y la define como «llovizna, en casi todo Sur América, aun en Cuba y Guatemala» ${ }^{22}$. Malaret alirma que en América Central, Argentina, Bolivia, Cuba, Chile, Ecuador, Panamá, Perú, Uruguay y Venezuela es 'llovizna' ${ }^{23}$. Neves trae la localización en

Intemacional de El español de Anérica, Valladolid, 3 a 9 de julio de 1989, Junta de Castilla y León, Consejería de Cultura y Turismo, Salamanca, 3 tomos: tomo III, págs. 1567-1578.

15 J. Casares, Diccionario ideológico de la lengua española, Gustavo Gili, Barcelona, 1981, $2^{\text {a }}$ edición, $10^{\mathrm{n}}$ tirada.

16 Respecto a esta obra dice M. Alvar Ezquerra que el interés del diccionario «no se centraba en el volumen y procedencia de las palabras, sino en el modo de ordenarlas, razón por la cual no hay ninguna referencia a los indigenismos americanos», en «La recepción de americanismos...», loc. cit., pág. 215.

$\mathrm{M}^{\mathrm{a}}$ Moliner, Diccionario de uso del español, Gredos, Madrid, 1982, reimpresión, 2 tomos. Suponemos que «Hispam.» significa «Hispanoamérica». No se indica en ningún lugar del Diccioncrio esta abreviatura.

18 M. Alvar Ezquerra, Diccionario Actual de la Lengua Española, Biblograf, Barcelona, 1991, I" edición, reimpresión. Vid. esta misma obra con el título Diccionario General de la Lengua Expañola, Biblograi, Barcelona, 1997.

19) A. de Alcedo, Diccionario geográfico-histórico de las Indias Occidentales o América, tomo IV, en Biblioteca de Autores Españoles, Edición y estudio preliminar de don Ciriaco PérezBustamente, Allas, Madrid, 1967.

20 M. A. Morínigo, Diccionario de Americanismos, Muchnik Editores, Barcelona, 1985, $2^{\text {a }}$ edición.

21 Ibídem.

22 F. J. Santamaría, Diccionario General de Americanismos, Editorial Pedro Robredo, Méjico, 1942,3 tomos.

23 A. Malaret, Diccionario de Americanismos, Emecé Editores, Buenos Aires, 1946, $3^{\mathrm{a}}$ edición. 
América y el significado de 'llovizna'24. Bayo para Centro y Sudamérica la recoge como 'calabobos, chilche. Voz muy extendida'25. Buesa y Enguita registran garía 'lluvia menuda' en América, excepto Méjico y Santo Domingo, como voz que proviene del gallego-portugués ${ }^{26}$. El Diccionario de Americanismos Sopena dice que es 'llovizna, lluvia fina o menuda que cac suavemente ${ }^{27}$. Arias trae la voz con localización en América y el significado de "llovizna' ${ }^{28}$. Steel ofrece garúa de origen portugués y el significado de "Ilovizna ${ }^{29}$ y la siguiente cita de Alejo Carpentier:

y entonces comparaba el joven, en su memoria auditiva, la diferencia que había cntre las lluvias del trópico y las monótonas garúas del Viejo Mundo ${ }^{30}$.

Hemos visto que, al igual que los diccionarios de lengua, los diccionarios generales de americanismos traen la voz como 'llovizna'. Lo cual indica que el término está bien localizado por los primeros. Veamos ahora los diccionarios o vocabularios de los diversos países hispanoamericanos.

Arona para Perú dice que garía es «llovizna menuda, o como dicen nuestros escritores del siglo pasado mollizna [...]; rocío, que puede caer en cualquier parte y que constituye la única llıvia del litoral peruano, extensión como de quinientas leguas de arenales desiertos, con risueños valles interpuestos [...]. El americanismo garía es uno de esos provincialismos sin suerte que tardan en aparecer, como ya lo hemos notado en otros de la laya: y lo llamamos americanismo, porque no lo creemos, ni peruanismo ni hispanismo de Américà ${ }^{3 !}$.

Hemos utilizado también un informante limeño: Luis Medina Vargas, nacido en Lima en 1963, 27 años, estudiante universitario. La encuesta se hizo en febrero de 1991. Nos dijo que la garúa es «lluvia menuda que se percibe sólo en el momento en que entra en contacto con la piel al estar la ropa húmeda. Uno no se da cuenta de que está cayendo pero cala. Una lluvia menuda que no se siente caer las gotas. Lluvia muy fina».

24 A. N. Neves, Diccionario de Americanismos, Editorial Sopena Argentina, Buenos Aires, 1975, $2^{\text {a }}$ edición. Vid., también, P. Boyd-Bowman, Léxico hispanoamericano del siglo XX, The Hispanic Seminary of Medieval Studies, Madison, 1994. Madrid, 1931

C. Bayo, Manual del lenguaje criollo de Centro y Sudamérica, Rafael Caro Raggio, editor,

26. T. Bucsa Oliver; J. Ma Enguita Utrilla, Léxico del español de América: su elemento patrimonial e indigena, Mapfre, Madrid, 1992.

27 Americanismos. Diccionario ilustrado Sopena, Editorial Ramón Sopena, Barcelona, 1982.

28 M. A. Arias de la Cruz, Diccionario temático. Americanismos, Editorial Everest, León, 1987, 2x edición.

20) B. Steel, Diccionario de Americanismos. ABC of Latin American Spanish, Sociedad General Española de Librería, Alcobendas (Madrid), 1990.

30) A. Carpentier, El siglo de las luces, Seix Barral, Barcelona, 1983, pág. 167.

31 J. de Arona, Diccionario de pertianismos, Ediciones Peisa, Lima, 1975, $3^{\text {a }}$ edición, 2 tomos, citamos por aquí. La primera edición es de la Imprenta de J. Fco. Solís, Lima, 1883. 
Alvarado para Venezuela dice que es 'lloviznita, mollizna' y añade «voz quichua usada en el Oriente y Caracas: en el quichua ecuatoriano garuana, lo mismo». Continua afïrmando que se usa también en Chile y Argentina ${ }^{32}$. Tejera trae también para Venezuela la voz con el significado de 'lluvia tenue y pasajera' ${ }^{33}$.

Gagini para Costa Rica ofrece «garúa por llovizna, mollizna, cernidillo, matapolvo y garuar por lloviznar, molliznar, figuran como peruanismos en el léxico oficial. Garía es de uso antiguo, pues lo encontramos en uno de nuestros documentos históricos (1719)»34. Quesada Pacheco trae garúa 'Ilovizna' ${ }^{35}$.

Para Río de la Plata, Granada registra la voz igualmente como 'llovizna' y añade: «en Lima, de donde quizás venga el vocablo, llaman de muy antiguo garía a la finísima llovizna en que se condensan las nieblas que durante el invierno oscurecen el cielo» ${ }^{36}$. Recoge una cita del Padre Lozano de la Historia de la Conquista del Paraguay, Río de la Plata y Tucumán:

Es por extremo enemiga de la lluvia, principalmente de la más menuda que llamamos garúa ${ }^{37}$.

Guarnieri también para Río de la Plata, concretamente con la etiqueta de chilenismo, trae la voz como 'llovizna'38.

Fernández Naranjo para Bolivia, igualmente, 'llovizna',3'.

32 L. Alvarado, Glosario de voces indigenas de Venezuela, Ediciones «Victoria», Caracas, 1921; Ídem, Glosarios del bajo español en Venezuela, Litografía-Tipografía Mercantil, Caracas, 1929. Citamos por la segunda edición: L. Alvarado, Obras completas. Tomo I: Glosario de voces indigenas de Venezuela. Voces geográficas; tomo II: Glosarios del bajo español en Venezuela. Primera parte. Acepciones especiales; tomo III: Glosarios del bajo español en Venezuela. Segunda parte. Neologismos y arcaísmos, Ministerio de Educación, Dirección de Cultura y Bellas Artes, Comisión Editora de las Obras completas de Lisandro Alvarado, Caracas (Venezuela), 1953-1955.

$33 \mathrm{M}^{\mathrm{a}} \mathrm{J}$. Tejera (Directora), Diccionario de Venezolanismos, Academia venezolana de la lengua, Universidad Central de Venezuela, Facultad de Humanidades y Educación, Instituto de Filología «Andrés Bello», Caracas, 1983-1994, 3 tomos.

34 C. Gagini, Diccionario de Barbarismos y Provincialismos de Costa Rica, Tipografía Nacional, San José de Costa Rica, 1892, $1^{\text {a }}$ edición; Diccionario de costarriqueñismos, Trejos Hermanos, Librería, Imprenta y Encuadernación, San José de Costa Rica, 1918 [fecha de las «Advertencias»], $2^{\text {a }}$ edición; Diccionario de costarriqueñismos, Biblioteca Patria, Editorial Costa Rica, San José de Costa Rica, 1975, $3^{a}$ edición. Hemos consultado ésta última.

35 M. A. Quesada Pacheco, Nuevo diccionario de costarriqueñismos, Editorial Tecnológica de Costa Rica, Cartago, 1991.

36 D. Granada, Vocabulario rioplatense razonado, precedido de un juicio crítico del Dr. Don Alejandro Magariños Cervantes, Imprenta Elzeviriana, Montevideo, 1889. Citamos por esta edición. Hay otra con el mismo título de la Imprenta Rural, Montevideo, 1890.

37 Ibidem.

38 J. C. Guarnieri, Diccionario del lenguaje rioplatense, Ediciones de la Banda Oriental, Montevideo, 1979. Sobre Río de la Plata, vid., además, A. Castro, La peculiaridad lingiiística rioplatense, Taurus, Madrid, 1960. 
Pichardo para Cuba registra garúa 'sinónimo de LLOVIZNA, aún más menuda ó leve' y garuar 'lloviznar más menuda ó levemente' ${ }^{\text {40 }}$.

Tobar Donoso para Ecuador dice de garúa «admitido como americanismo, por llovizna; pero también se lo emplea en Murcia. Se ha acogido igualmente el verbo garuars ${ }^{41}$.

Valle para Nicaragua lo recoge como voz quichua y el significado de "llovizna, chipiza"42.

Morales Pettorino para Chile ofrece garúa (del portugués caruja 'niebla'), término familiar con el significado de 'acción y efecto de garuar' y garuar como 'lloviznar, caer llovizna menuda' ${ }^{43}$. Para Chile recogen la voz con este mismo significado Echevarría ${ }^{44}$, Oroz ${ }^{45}$, Rodríguez ${ }^{46}$, Román ${ }^{47}$.

Para Argentina, Toro dice que

GARÚA, bruine, GARUAR, bruiner sont des mots quichuas pour Segovia, comme pour l'Académie espagnole. Granada donne garúa, sans étimologie, en ajoutant que le mot s'emploie au Chili et au Pérou, et en note des citations d'Ulloa et du P. Lozano. Lafone Quevedo indique la forme garuga et croit improbable l'étimologie quichua. Le mot s'emploie jusqu'en Amérique Centrale, à Cuba et à Porte-Rico.

31) N. Fernández Naranjo, Diccionario de bolivianismos, Editorial «Los amigos del Libro», La Paz-Cochabamba, 1980, 4ª edición, ocho suplementos. La segunda edición es de 1967; la tercera de 1975.

41 E. Pichardo, Diccionario provincial de voces cubanas, Imprenta de la Real Marina, Matanzas, 1836, citamos por aquí. Hay otras muchas ediciones: Diccionario provincial cuasirazonado de voces cubanas, Matanzas, 1849; La Habana, 1861; La Habana, 1875; Diccionario provincial casi razonado de vozes y frases cubanas, corregido y anotado por el Dr. Esteban Rodríguez Herrera, Editorial Selecta, La Habana, 1953.

41 J. Tobar Donoso, El lenguaje rural en la región interandina del Ecuador. Lo que falta y lo que sobra, Publicaciones de la Academia Ecuatoriana, Editorial «La Unión Católica», Quito (Ecuador), 1961: \$1275.

42 A. Valle, Diccionario del habla nicaragïense, Impreso en la editorial «La nueva prensa», Managua D. N. (Nicaragua, C. A.), 1948.

4.3 F. Morales Pettorino (Director); O. Quiroz Mejías (Investigador principal); J. J. Peña Álvarez (Investigador adjunto), Diccionario ejemplificado de chilenismos y de otros usos diferenciales del español de Chile, Academia Superior de Ciencias Pedagógicas de Valparaíso, Santiago de Chile, 1984-1987, 4 tomos..

${ }_{44}$ A. Echevarría y Reyes, Voces usadas en Chile, Imprenta Elzeviriana, Santiago de Chile, 1900 .

${ }^{4}$ R. Oroz, La lengua castellana en Chile, Facultad de Filosofía y Educación, Universidad de Chile, Santiago, 1966.

46 Z. Rodríguez, Diccionario de chilenismos, Imprenta el Independiente, Santiago de Chile, 1875.

47 M. A. Román, Diccionario de chilenismos y de otras voces y locuciones viciosas, Imprenta de «La Revista Católica», Santiago de Chile, 1901-1908, 5 tomos. 
Il est d'origine espagnole. Nous avons en canarien garuja, avec le même $\operatorname{sens}^{48}$.

Haensch y Werner para Argentina dicen que es término coloquial 'lluvia fina y persistente' que en España tiene uso regional y los sinónimos de 'calabobos, chirimiri, llovizna', y garuar 'caer una lluvia fina y persistente ${ }^{49}$. Lafone Quevedo recoge en Catamarca (Argentina) garuga 'Ilovizna' y añade «también decimos garía, teniendo a esta por más esmerada que la primera ${ }^{50}$.

Para Uruguay, Haensch y Werner registran garúa 'lluvia fina y persistente' y añaden que en España con esta acepción es sólo de uso regional ${ }^{5 !}$.

Hemos constatado que el término garúa está bien registrado como americanismo en los diccionarios de lengua española, en los diccionarios de americanismos y en los diccionarios particulares de distintos países americanos. Hasta aquí todo está bien. Lo que sucede es que la voz, además de utilizarse en América, se usa también — como se ha ligeramente apuntado- en Canarias, siendo moneda corriente en las Islas desde donde viajaría al Nuevo Mundo.

El Atlas lingïístico y etnográfico de las Islas Canarias (ALEICan) $)^{52}$ recoge garía, garuja, jarija como 'agua menudita que parece que no moja, pero nos Cala ${ }^{53}$.

Garía en La Graciosa, Fuerteventura y La Palma ${ }^{54}$; garuja en Lanzarote, Gran Canaria y Gomera ${ }^{55}$; jarija en Lanzarote y Gomera ${ }^{56}$. Como es habitual en Canarias encontramos la -j-aspirada, de ahí garuha y hariha.

Según los datos del Léxico de los Marineros Peninsulares $(L M P)^{57}$, garuja 'Ilovizna' en Fuerteventura y Lanzarote ${ }^{58}$, 'lluvia poco densa' en Lanzarote,

48 M. de Toro, L'évolution de la langue espagnole en Argentine, Librairie Larousse, París, sin año: $\$ 57$

4) G. Haensch; R. Werner (Directores), Nuevo Diccionario de Americanismos, tomo II: C. Chuchuy; L. Hlavacka de Bouzo (Coordinadores), Nuevo Diccionario de Argentinismos, Instituto Caro y Cuervo, Santafé de Bogotá, 1993.

50) S. A. Lafone Quevedo, Tesoro de catamarqueñismos, completada con Palabras y modismos en Catamarca por F. F. Avellaneda, Imprenta y Casa Editorial «Coni», Buenos Aires, 1927, $3^{\text {* }}$ edición.

51 G. Haensch; R. Werner (Directores), Nuevo Diccionario de Americanismos, tomo III: U. Kühl de Mones, Nuevo Diccionario de Uruguayismos, Instituto Caro y Cuervo, Santafé de Bogotá, 1993.

2 M. Alvar, Atlas lingüístico y etnográfico de las Islas Canarias, Ediciones del Excmo. Cabildo Insular, Las Palmas, tomo I, 1975; tomo II, 1976; tomo III, 1978.

5.3 ALEICan, II, 758. Acerca del análisis de este mapa en las Islas, vid. nuestro trabajo, Comentario de mapas lingäísticos españoles, Universidad de Alicante, Alicante, 1998.

5.t Gs 1; Fv 31; LP 1.

$55 \mathrm{Lz} 2,4,10,20 ; \mathrm{GC} 2$ (garujilla); Go 3 (jaruja).

$56 \mathrm{Lz} 2,4 ; \mathrm{Go} 40$.

57 M. Alvar, Léxico de los marineros peninsulares, Arco Libros, Madrid, tomos I y II, 1985; tomos III y IV, 1989.

58 LMP, I, 100: Fv 2; Lz 2 . 
Fuerteventura, Gran Canaria, Tenerife y Gomera"; garía 'llovizna' en La Graciosa y Gran Canaria ${ }^{(i)}$, y 'Iluvia poco densa' en Gran Canaria menuda' y en Lanzarote y Fuerteventura 'niebla que trae una lluvia muy menuda' según Lorenzo, Morera y Ortega ${ }^{62}$. Jarija 'Ilovizna' en Gran Canaria e Hierro ${ }^{6.3}$.

Llorente clasifica garía/garuga, garuja como «portuguesismos». Dice que

Garuja y sus numerosas variantes fonéticas están atestiguadas en todas las islas, menos [...] en Hi y Tf, alternando con distintos interesantes sinónimos, teniendo en cuenta que ni garuja ni ninguna de sus variantes aparecen en Andalucía, ni siquiera en Huelva [...], y que en portugués tenemos las formas caruja 'llovizna' y carujar 'Iloviznar', parece claro que se trata de un préstamo portugués al habla de las Canarias. Durante cierto tiempo garuja, garúa, garuga han sido consideradas como distintas manifestaciones fonéticas del americanismo, de la palabra amerindia garúa, quizá por la vitalidad que tiene este vocablo en determinadas áreas del español de América, sobre todo en el Perú, donde designa un fenómeno meteorológico habitual y característico de la costa limeña. No tiene nada de particular que la creencia en el carácter americano, más concretamente en el carácter quechua, de garúa haya llegado hasta nuestros días y que los hermanos Millares estuvieran convencidos de que garía y sus variantes son de origen americano [...], es evidente que tanto las formas garuja, garía, garuga, propias del dominio linguístico español, como la palabra portuguesa correspondiente caruja 'llovizna, niebla húmeda, rocío' son formas románicas procedentes de la etimología caligine/ *calugine. Ahora bien, lo que no está tan claro, en principio, es si garúa, garuja, garuga son voces patrimoniales castellanas o si proceden del portugués [...]. En definitiva garuja (y sus variantes) es un portuguesismo [...] y desde [Canarias] pasó a América ${ }^{64}$.

Lorenzo afirma que garúa, garuga, garuja 'llovizna, especialmente en el mar' es portuguesismo ${ }^{65}$. Para Díaz Alayón garua, garuga es a) 'Rebozo en el mar' (San Andrés, Las Llanadas y Santo Domingo). b) 'Lluvia menos abundante que el

59) LMP, I, 100: Lz 2; FV 2; GC 4; Tf 2; Go 1 (garuga).

(6) LMP, I, 100: Gs 1; GC 1 .

6) $L M P, \mathrm{I}, 100: \mathrm{GC}$ ।

62 A. Lorenzo Ramos; M. Morera; G. Ortega, Diccionario de canarismos, Francisco Lemus Editor, La Laguna, 1995. Sobre la voz garía vid. toda la documentación en C. Corrales Zumbado; D. Corbella Díaz; M A. Álvarez Martínez, Tesoro lexicográfico del español de Canarias, Real Academia Española-Gobierno de Canarias, Consejería de Educación, Cultura y Deportes, Madrid, 1992.

6.3 LMP, I, 101: GC 3; Hi I.

64. A. Llorente, «Comentario de algunos aspectos del léxico del tomo Il del ALEICan», I Simposio Internacional de Lengua Española (1978), Excmo. Cabildo Insular de Gran Canaria, Las Palmas de Gian Canaria, 1981, págs. 193-224.

65 A. Lorenzo Ramos, «Sobre el léxico regional canario», en Rumbos n 7 (1982), págs. $5[-64$. 
aguacero' (San Andrés). c) 'Lluvia débil' (Las Llanadas y Santo Domingo) ${ }^{66}$. Almeida y Díaz Alayón recogen, así mismo, garía, garuja 'lluvia menuda' ${ }^{67}$; garúa, garuga, garuja y garujar 'lloviznar muy ligera pero persistentemente' en O'Shanahan ${ }^{68}$.

Garujilla 'mollizna' en Pícar ${ }^{69}$. Para Millares «garuja, del americanismo «garúa», es llovizna y garujear es lloviznar. - ¿Llueve? - No señor: no son más que garujas: está garujiando»". Wagner dice que garuja es 'llovizna' del portugués dialectal caruja 'orvalho, ${ }^{, 71}$. Álvarez, a propósito de esta voz, afirma lo siguiente:

Wagner [...] considera [que la palabra garuja] debe incluirse entre los portuguesismos de Canarias, como derivado del port. caruja, «rocío». Hoy queremos citarlo para señalar la forma vasca garo, «rocío», que Castro Guisasola relacionó con un radical indoeuropeo de significado de «agua» y la forma canaria garoé, nombre del árbol del Hierro, y una forma, también vasca, garoa, «helecho», aplicados a plantas destiladoras de agua o húmedas por el rocío. Esto indica, por lo menos, la necesidad de estudiar la geografía de la forma portuguesa caruja y del canarismo garuja, y sus paralelas de otros dialectos hispánicos, para ver si nos encontramos efectivamente, ante una forma romance, $o$ ante un elemento de substrato iberoafricano, conservado en portugués, vasco y canario. El problema por difícil, no deja de ser curioso ${ }^{72}$.

Régulo en una reseña que le hace a este trabajo de Álvarez Delgado afirma que Corominas se inclinó por un étimo románico y que Luis Jaime Cisneros en un artículo titulado «Garúa románico» (Orbis, III, (1954), págs. 211-223), que Álvarez no pudo consultar por la fecha de su aparición, «ha aducido numerosísimos testimonios y referencias de los siglos XVI y XVII, que coinciden en afirmar la oriundez románica y descartar las propuestas procedencias vasca, quechua o peruana; parece ser que se trata de una "palabra viajera» de origen marinero» ${ }^{73}$.

66 C. Díaz Alayón, «Nuevas aportaciones al léxico de la lluvia en La Palma», Revista de Filología de la Universidad de La Laguna, 2 (1983), págs. 71-80.

67 M. Almeida; C. A. Díaz Alayón, El español de Canarias, Santa Cruz de Tenerife, 1988.

68 A. O'Shanahan, Gran diccionario del habla canaria. Más de 13.000 voces y frases isleñas, de utilidad para propios y ajenos, recogidas de la tradición oral y escrita, Centro de la Cultura Popular Canaria, Madrid, 1995.

6) M. Pícar y Morales, «Anotaciones explicativas», en Ageneré (novela), Las Palmas de Gran Canaria, 1905, págs. 79-99.

7) A. Millares Cubas, Cómo hablan los canarios (Refundición del Léxico de Gran Canaria (1924), de Luis y Agustín Millares Cubas), Las Palmas de Gran Canaria, 1932.

71 M. L. Wagner, «Notas bibliográficas al Léxico de Gran Canaria de L. y A. Millares», RFE, Xll (1925), págs. 78-86.

72. J. Álvarez Delgado, «Nuevos canarismos», RDTP, IV (1948), págs. 434-453.

73 J. Régulo Pérez, Reseña de «Nuevos canarismos» de J. Álvarez Delgado, Revista de Historia Canaria, XIX (1948), págs. 108-112. 
Garujas 'gotas de agua de lluvia' en Cabrera ${ }^{74}$. Guerra dice que es «lluvia menuda (el «sirimiri» vasco o el «calabobos» castellano, el «orballo» gallego)» ${ }^{75}$. Santiago lo trae también como 'Iluvia fina, chirimiri ${ }^{76}$. Pérez Vidal acerca de esta voz afirma lo siguiente:

La sonorización de la inicial oclusiva sorda $c$ que se da en [...] garuja 'Ilovizna' responde a una tendencia general de la lengua popular portuguesa, que aparece ya en latín vulgar. Existe también en castellano ${ }^{77}$.

\section{Lorenzo dice que}

en Los Silos garuja parece ser una 'Iluvia muy menuda'; también hemos recogido las variantes garuga, jaruja y garía ${ }^{78}$.

En cuanto a jarija, Martí da el significado de 'aguas serenas' y añade:

Aquí, en la tierra, cuando llueve un poquito, un agüita serena, que por tierras de fuera parece que se dice calabobos y que alguien llama sorimba, solemos decir que está cayendo una jarija. Una jarija, que si se aguanta, y anda uno despacio, acaba por dejarnos enchumbados ${ }^{79}$.

C. Corrales y D. Corbella registran garúa en su Diccionario de las coincidencias léxicas entre el español de Canarias y el español de América ${ }^{80}$, dicen que procede del portugués caruja y la localizan en Fuerteventura, Gran Canaria, Gomera, La Palma y Tenerife con el significado de 'llovizna fina, generalmente con niebla' y en una segunda acepción dicen 'lo mismo' en Argentina, Bolivia, Chile, Colombia ${ }^{81}$, Costa Rica, Cuba (desusado), Ecuador, Nicaragua, Panamá, Paraguay, Perú, Puerto Rico (desusado), Uruguay y

74 P. Cabrera Perera, «Voces de la provincia de Las Palmas (Gran Canaria, Lanzarote y Fuerteventura)», RDTP, XVII (1961), págs. 365-373.

75 F. Guerra Navarro, Contribución al léxico popular de Gran Canaria, Ediciones «Peña Pancho Guerra», Madrid, 1965.

76 M. Santiago, «Vocabulario empleado por Pancho Guerra en sus tres obras Cuentos famosos de Pepe Monagas (1948), Memorias de Pepe Monagas (1958), Siete Entremeses de Pepe Monagas (1962)», en F. Guerra Navarro, Contribución al léxico popular de Gran Canaria, Ediciones «Peña Pancho Guerral», Madrid, 1965, págs. 545-808.

77 J. Pérez Vidal, «Comportamiento fonético de los portuguesismos en Canarias», RDTP, XXIV (1968), págs. 219-252.

78 A. Lorenzo Ramos, El habla de Los Silos, Caja General de Ahorros de Santa Cruz de Tenerife, Santa Cruz de Tenerife, 1976 [se presentó como Tesis doctoral en 1973], págs. 77-185.

79) A. Martí, Ansina jabla la isla, Algol, Santa Cruz de Tenerife, 1986, 4 tomos: tomo IV.

80) Cabildo de Tenerife, Santa Cruz de Tenerife, 1994.

\&I No figura en G. Haensch; R. Werner (Directores), Nuevo Diccionario de Americanismos, tomo I: Nuevo Diccionario de Colombianismos, Instituto Caro y Cuervo, Santafé de Bogotá, 1993. 
Venezuela, y como 'neblina, niebla' es americanismo (excepto en Méjico y Santo Domingo; desusado en Cuba y Puerto Rico).

De garúc, Corominas dice que es término americano y marítimo que significa 'llovizna' y antiguamente 'niebla'. En Canarias —indica el etimólogo- se pronuncia garuja y está tomado del portugués dialectal carıja 'niebla', procedente del latín vulgar *CALUGO, -UGINIS, variante del latín CALIGO, -INIS; de *CALUGINEM salió *caúgem, y luego, por contaminación de un sinónimo *carugem y caruja ${ }^{82}$. García de Diego recoge garuga 'niebla y llovizna' en Canarias y afirma que procede de garúa con $g$ epentética ${ }^{8.3}$. Nosotros, en cambio, creemos que en la forma garúa se ha perdido la -g- de garuga o garuja.

\section{A modo de conclusión}

Hemos visto cómo la localización que da el $D R A E-92$ de la voz garúa es inexacta. La compilación académica podría ampliar la localización de dicha voz que no sólo se halla en América sino que es usual en las Islas Canarias ${ }^{84}$, hecho que hemos podido comprobar con la ayuda del Atlas lingiiistico y etnográfico de las Islas Canarias y con otras obras sobre el español de las Islas, tanto vocabularios y léxicos como trabajos de carácter dialectal. A partir de esta localización canaria que tiene la voz podemos preguntarnos si se puede considerar un americanismo o un dialectalismo del español canario, o las dos cosas a la vez. Garúa, portuguesismo en Canarias, tuvo que viajar desde las Afortunadas hasta el Nuevo Mundo donde ahora también se encuentra.

\section{Referencias bibliográficas}

Alcedo, A. de, Diccionario geográfico-histórico de las Indias Occidentales o América, tomo IV, en Biblioteca de Autores Españoles, Edición y estudio preliminar de don Ciriaco Pérez-Bustamente, Atlas, Madrid, 1967.

Almeida, M.; C. A. Díaz Alayón, El español de Canarias, Santa Cruz de Tenerile, 1988.

Alvar, M., Atlas lingüístico y etnográfico de las Islas Canarias, Ediciones del Excmo. Cabildo Insular, Las Palmas, tomo I, 1975; tomo II, 1976; tomo III, 1978.

- Léxico de los marineros peninsulares, Arco Libros, Madrid, tomos I y II, 1985; tomos III y IV, 1989.

\$2 J. Corominas; J. A. Pascual, Diccionario Crítico Etimológico Castellano e Hispánico, Gredos, Madrid, 1980-1991, 6 tomos: s. v. Garúa.

\$.3. V. García de Diego, Diccionario Etinológico Español e Hispánico, Espasa-Calpe, Madrid, 1985, 2" edición: s. v. Caligo, -inis.

it Respecto a las voces canarias que no son recogidas por el $D R A E-92$, vid. nuestro trabajo, $E l$ Allas de Cancirias y el Diccionario Acadénico, Universidad de Alicante, Alicante, 1996. 
Alvar Ezquerra, M., «La recepción de americanismos en los diccionarios generales de la lengua», en $\mathrm{H}$. López Morales y $\mathrm{M}^{\mathrm{a}}$. Vaquero (Editores), Actas del I Congreso Internacional sobre El español de América, San Juan, Puerto Rico, del 4 al 9 de octubre de 1982, Academia Puertorriqueña de la Lengua Española, Puerto Rico, 1987, págs. 209-218.

- Diccionario Actual de la Lengua Española, Biblograf, Barcelona, 1991, $1^{2}$ edición, reimpresión.

- Diccionario General de la Lengua Española, Biblograf, Barcelona, 1997.

Alvarado, L., Glosario de voces indígenas de Venezuela, Ediciones «Victoria», Caracas, 1921; Glosarios del bajo español en Venezuela, LitografíaTipografía Mercantil, Caracas, 1929; Obras completas, tomo I: Glosario de voces indígenas de Venezuela. Voces geográficas; tomo II: Glosarios del bajo español en Venezuela. Primera parte. Acepciones especiales; tomo III: Glosario del bajo español en Venezuela. Segunda parte. Neologismos y arcaísmos, Ministerio de Educación, Dirección de Cultura y Bellas Artes, Comisión Editora de las Obras completas de Lisandro Alvarado, Caracas (Venezuela), 1953-1955.

Álvarez Delgado, J., «Nuevos canarismos», RDTP, IV (1948), págs. 434-453.

Arias de la Cruz, M. A., Diccionario temático. Americanismos, Editorial Everest, León, 1987, $2^{a}$ edición.

Arona, J. de, Diccionario de peruanismos, Ediciones Peisa, Lima, 1975, $3^{\text {a }}$ edición, 2 tomos. La primera edición está publicada por la Imprenta de J. Fco. Solís, Lima, 1883.

Bayo, C., Manual del lenguaje criollo de Centro y Sudamérica, Rafael Caro Raggio, editor, Madrid, 1931.

Boyd-Bowman, P., Léxico hispanoamericano del siglo $X X$, The Hispanic Seminary of Medieval Studies, Madison, 1994.

Buesa Oliver, T.; J. Ma Enguita Utrilla, Léxico del español de América: su elemento patrimonial e indígena, Mapfre, Madrid, 1992.

Cabrera Perera, P., «Voces de la provincia de Las Palmas (Gran Canaria, Lanzarote y Fuerteventura)», RDTP, XVII (1961), págs. 365-373.

Carpentier, A., El siglo de las luces, Seix Barral, Barcelona, 1983.

Casares, J., Diccionario ideológico de la lengua española, Gustavo Gili, Barcelona, 1981, 2a edición, $10^{\mathrm{a}}$ tirada.

Castro, A., La peculiaridad lingiiística rioplatense, Taurus, Madrid, 1960. Corominas, J.; J. A. Pascual, Diccionario Crítico Etimológico Castellano e Hispánico, Gredos, Madrid, 1980-1991, 6 tomos.

Corrales Zumbado, C.; D. Corbella Díaz; $\mathrm{M}^{\mathrm{a}}$ A. Álvarez Martínez, Tesoro lexicográfico del español de Canarias, Real Academia Española-Gobierno de Canarias, Consejería de Educación, Cultura y Deportes, Madrid, 1992.

-; -; Diccionario de las coincidencias léxicas entre el español de Canarias y el español de América, Cabildo de Tenerife, Santa Cruz de Tenerife, 1994. 
Díaz Alayón, C., «Nuevas aportaciones al léxico de la lluvia en La Palma», Revista de Filología de la Universidad de La Laguna, 2 (1983), págs. 71-80.

Echevarría y Reyes, A., Voces usadas en Chile, Imprenta Elzeviriana, Santiago de Chile, 1900.

Fernández Naranjo, N., Diccionario de bolivianismos, Editorial «Los amigos del Libro», La Paz-Cochabamba, 1980, $4^{\text {a }}$ edición, ocho suplementos; 1967, $2^{\mathrm{a}}$ edición; $1975,3^{\text {a }}$ edición.

Gagini, C., Diccionario de Barbarismos y Provincialismos de Costa Rica, Tipografía Nacional, San José de Costa Rica, 1892, $1^{\text {a }}$ edición; Diccionario de costarriqueñismos, Trejos Hermanos, Librería, Imprenta y Encuadernación, San José de Costa Rica, 1918 [fecha de las «Advertencias»], $2^{a}$ edición; Diccionario de costarriqueñismos, Biblioteca Patria, Editorial Costa Rica, San José de Costa Rica, 1975, $3^{\text {a }}$ edición.

García de Diego, V., Diccionario Etimológico Español e Hispánico, EspasaCalpe, Madrid, 1985, $2^{\text {a }}$ edición.

García Soriano, J., Vocabulario del dialecto murciano, Editora Regional, Murcia, 1980, edición facsímile de la primera, Madrid, 1932.

Granada, D., Vocabulario rioplatense razonado, precedido de un juicio crítico del Dr. Don Alejandro Magariños Cervantes, Imprenta Elzeviriana, Montevideo, 1889. Hay otra edición con el mismo título: Imprenta Rural, Montevideo, 1890.

Guarnieri, J. C., Diccionario del lenguaje rioplatense, Ediciones de la Banda Oriental, Montevideo, 1979.

Guerra Navarro, F., Contribución al léxico popular de Gran Canaria, Ediciones «Peña Pancho Guerra», Madrid, 1965.

Gútemberg Bohórquez, J., Concepto de 'americanismo' en la historia del español. Punto de vista lexicológico y lexicográfico, Publicaciones del Instituto Caro y Cuervo, Bogotá, 1984.

Haensch, G., «Algunas consideraciones sobre la problemática de los diccionarios del español de América», Linguiística Española Actual, II/2 (1980), págs. 375384.

—; R. Werner, «Un nuevo diccionario de americanismos: Proyecto de la Universidad de Augsburgo», Thesaurus. Boletín del Instituto Caro y Cuervo, XXIII (1978), Bogotá, citamos por la separata, págs. 1-40.

-; - (Directores), Nuevo Diccionario de Americanismos, tomo I: Nuevo Diccionario de Colombianismos, Instituto Caro y Cuervo, Santafé de Bogotá, 1993.

-; - (Directores), Nuevo Diccionario de Americanismos, tomo II: C. Chuchuy;

L. Hlavacka de Bouzo (Coordinadores), Nuevo Diccionario de Argentinismos, Instituto Caro y Cuervo, Santafé de Bogotá, 1993. 
-; - (Directores), Nuevo Diccionario de Americanismos, tomo III: U. Kühl de Mones, Nuevo Diccionario de Uruguayismos, Instituto Caro y Cuervo, Santafé de Bogotá, 1993.

Lafone Quevedo, S. A., Tesoro de catamarqueñismos, completado con Palabras y modismos en Catamarca por F. F. Avellaneda, Imprenta y Casa Editorial «Coni», Buenos Aires, 1927, $3^{\text {a }}$ edición.

Llorente, A., «Comentario de algunos aspectos del léxico del tomo II del ALEICan», I Simposio Internacional de Lengua Española (1978), Excmo. Cabildo Insular de Gran Canaria, Las Palmas de Gran Canaria, 1981, págs. 193-224.

Lorenzo Ramos, A., El habla de Los Silos, Caja General de Ahorros de Santa Cruz de Tenerife, Santa Cruz de Tenerife, 1976 [se presentó como Tesis doctoral en 1973].

—, «Sobre el léxico regional canario», en Rumbos nº 7 (1982), págs. 51-64.

-; M. Morera; G. Ortega, Diccionario de canarismos, Francisco Lemus Editor, La Laguna, 1995.

Malaret, A., Diccionario de Americanismos, Emecé Editores, Buenos Aires, 1946, $3^{\text {a }}$ edición.

Martí, A., Ansina jabla la isla, Algol, Santa Cruz de Tenerife, 1986, 4 tomos.

Millares Cubas, A., Cómo hablan los canarios (Refundición del Léxico de Gran Canaria (1924), de Luis y Agustín Millares Cubas), Las Palmas de Gran Canaria, 1932.

Moliner, $\mathrm{M}^{\mathrm{a}}$., Diccionario de uso del español, Gredos, Madrid, 1982, rcimpresión, 2 tomos.

Montes Giraldo, J. J., Dialectología y geografía lingiiústica. Notas de orientación, Instituto Caro y Cuervo, Bogotá, 1970.

Morales Pettorino, F. (Director); O. Quiroz Mejías (Investigador principal); J. J. Peña Álvarez (Investigador adjunto), Diccionario ejemplificado de chilenismos y de otros usos diferenciales del español de Chile, Academia Superior de Ciencias Pedagógicas de Valparaíso, Santiago de Chile, 1984-1987, 4 tomos.

Morínigo, M. A., Diccionario de Americanismos, Muchnik Editores, Barcelona, 1985, $2^{a}$ edición.

Navarro Carrasco, A. I., "Americanismos en La tía Julia y el escribidor», en C. Hernández, G. de Granda, C. Hoyos, V. Fernández, D. Dietrick, Y. Carballera (Coordinadores), El español de América. Actas del III Congreso Internacional de El español de América, Valladolid, 3 a 9 de julio de 1989, Junta de Castilla y León, Consejería de Cultura y Turismo, Salamanca, 3 tomos: tomo III, págs. 1567-1578.

-, El Atlas de Canarias y el Diccionario Académico, Universidad de Alicante, Alicante, 1996. 
- Comentario de mapas lingüísticos españoles, Universidad de Alicante, Alicante, 1998.

Neves, A. N., Diccionario de Americanismos, Editorial Sopena Argentina, Buenos Aires, 1975, $2^{\text {a }}$ edición.

Oroz, R., La lengua castellana en Chile, Facultad de Filosofía y Educación, Universidad de Chile, Santiago, 1966.

O'Shanahan, A., Gran diccionario del habla canaria. Más de 13.000 voces y frases isleñas, de utilidad para propios y ajenos, recogidas de la tradición oral y escrita, Centro de Cultura Popular Canaria, Madrid, 1995.

Pérez Vidal, J., «Comportamiento fonético de los portuguesismos en Canarias», RDTP, XXIV (1968), págs. 219-252.

Pícar y Morales, M., «Anotaciones explicativas», en Ageneré (novela), Las Palmas de Gran Canaria, 1905, págs. 79-99.

Pichardo, E., Diccionario provincial de voces cubanas, Imprenta de la Real Marina, Matanzas, 1836. Hay otras muchas ediciones: Diccionario provincial cuasi-razonado de voces cubanas, Matanzas, 1849; La Habana, 1861; La Habana, 1875; Diccionario provincial casi razonado de vozes y frases cubancs, corregido y anotado por el Dr. Esteban Rodríguez Herrera, Editorial Selecta, La Habana, 1953.

Quesada Pacheco, M. A., Nuevo diccionario de costarriqueñismos, Editorial Tecnológica de Costa Rica, Cartago, 1991.

Rabanales, A., Introducción al estudio del español de Chile. Determinación del concepto de chilenismo, Publicaciones del Instituto de Filología, Sección del Instituto de Investigaciones Histórico-culturales de la Facultad de Filosofía y Educación, Universidad de Chile, Anexo $n^{\circ} 1$ del Boletín de Filología, Santiago, 1953.

Real Academia Española, Diccionario de la lengua española, Espasa-Calpe, Madrid, 1984, 20ª edición, 2 tomos.

-, Diccionario de la lengua española, Espasa-Calpe, Madrid, 1992,21 a edición. Régulo Pérez, J., Reseña de «Nuevos canarismos» de J. Álvarez Delgado, Revista de Historia Canaria, XIX (1948), págs. 108-112.

Richard, R. (Coordinador), Diccionario de hispanoamericanismos no recogidos por la Real Academia, Cátedra, Madrid, 1997.

Rodríguez, Z., Diccionario de chilenismos, Imprenta el Independiente, Santiago de Chile, 1875.

Román, M. A., Diccionario de chilenismos y de otras voces y locuciones viciosas, Imprenta de la «Revista Católica», Santiago de Chile, 1901-1908, 5 tomos.

Rona, J. P., Aspectos metodológicos de la dialectología hispanoamericana, Montevideo, 1958.

-, «¿Qué es un americanismo?», en El Simposio de México, enero de 1968, actas, informes y comunicaciones, Méjico, 1969, págs. 135-148. 
Santamaría, F. J., Diccionario General de Americanismos, Editorial Pedro Robredo, Méjico, 1942, 3 tomos.

Santiago, M., «Vocabulario empleado por Pancho Guerra en sus tres obras Cuentos famosos de Pepe Monagas (1948), Memorias de Pepe Monagas (1958), Siete Entremeses de Pepe Monagas (1962)», en F. Guerra Navarro, Contribución al léxico popular de Gran Canaria, Ediciones «Peña Pancho Guerra», Madrid, 1965, págs. 545-808.

Seco, M., «El léxico hispanoamericano en los diccionarios de la Academia española», BRAE, LXVIII (1988), págs. 85-98.

Sopena, Americanismos. Diccionario ilustrado Sopena, Editorial Ramón Sopena, Barcelona, 1982.

Steel, B., Diccionario de Americanismos. ABC of Latin American Spanish, Sociedad General Española de Librería, Alcobendas (Madrid), 1990.

Tejera, $\mathrm{M}^{\mathrm{a}} \mathrm{J}$. (Directora), Diccionario de Venezolanismos, Academia Venezolana de la Lengua, Universidad Central de Venezuela, Facultad de Humanidades y Educación, Instituto de Filología «Andrés Bello», Caracas, 1983-1994, 3 tomos.

Tobar Donoso, J., El lenguaje rural en la región interandina del Ecuador. Lo que falta y lo que sobra, Publicaciones de la Academia Ecuatoriana, Editorial «La Unión Católica», Quito (Ecuador), 1961.

Toro, M. de, L'évolution de la langue espagnole en Argentine, Librairie Larousse, París, sin fecha.

Valle, A., Diccionario del habla nicaragüense, Impreso en la editorial «La nueva prensa», Managua D. N. (Nicaragua, C. A.), 1948.

Vargas Llosa, M., La tía Julia y el escribidor, Seix Barral, Barcelona, 1977; Seix Barral, Barcelona, 1984, $7^{\text {a }}$ edición.

Wagner, M. L., «Notas bibliográficas al Léxico de Gran Canaria de L. y A. Millares», RFE, XII (1925), págs. 78-86. 